\title{
Learning the Fundamentals of Traditional Chinese Medicine by Using Computer Courseware: A Preliminary Study
}

\author{
Shih Yu-ChihD', Lee, Yuan-Wen ${ }^{2,3}$, Tseng Sung-Hui $^{4,5}$, Chien Shu-Chen ${ }^{6,7}$, Wang Ching-Chiung ${ }^{8^{*}}$ \\ ${ }^{1}$ Department of English Language and Literature, Fu-Jen Catholic University, Taipei, Taiwan \\ ${ }^{2}$ Department of Anesthesiology, Taipei Medical University Hospital, Taipei, Taiwan \\ ${ }^{3}$ Department of Anesthesiology, School of Medicine, College of Medicine, Taipei Medical University, Taipei, Taiwan \\ ${ }^{4}$ Department of Rehabilitation, Taipei Medical University Hospital, Taipei, Taiwan \\ ${ }^{5}$ Department of Physical Medicine and Rehabilitation, School of Medicine, College of Medicine, Taipei Medical University, Taipei, Taiwan \\ ${ }^{6}$ Department of Clinical Pharmacy, School of Pharmacy, College of Pharmacy, Taipei Medical University, Taipei, Taiwan \\ ${ }^{7}$ Department of Pharmacy, Taipei Medical University Hospital, Taipei, Taiwan \\ ${ }^{8}$ School of Pharmacy, College of Pharmacy, Taipei Medical University, Taipei, Taiwan
}

\begin{abstract}
Context: The knowledge and terms of Traditional Chinese Medicine are abstract and difficult for students and the public to understand in the present day. Aim: This article describes the development of Traditional Chinese Medicine computer courseware on DVD and the study done for determining whether instructions designed digitally are as effective as the instructions explained in the traditional lectures for students to acquire awareness of the abstract concepts and terms of Traditional Chinese Medicine. Settings and Design: Two units on Traditional Chinese Medicine were taught to 198 Taiwanese students: 153 students studied using the traditional classroom lecture method and 45 students studied using computer courseware on DVD. Results: Quantitative data on pre-test and post-test and qualitative data on open-ended responses regarding the experience of using the courseware were collected and analyzed. The post-test scores of both the lecture group and DVD courseware group were significantly higher than the pre-test scores. However, the results showed that the score gains between the pre-test and post-test scores of the two groups did not differ. Qualitative responses demonstrated that the students responded positively to using courseware. Since we are not denying the effectiveness of the face-to-face lectures, this result indicated that welldesigned courseware is as effective as classroom lectures. Digital materials on the DVD courseware could assist learners for autonomous learning.
\end{abstract}

Key words: Traditional Chinese Medicine (TCM) Computer courseware, digital learning, Traditional Chinese Medicine (TCM), Taiwanese college learners, instructional design, animated story.

Key Messages: Educators in the field of Traditional Chinese Medicine (TCM) recognize that twenty-first century students are digital natives, not digital immigrants. In addition to traditional instructional methods, computer courseware enables students and the public to acquire the abstract knowledge of TCM effectively.

\section{INTRODUCTION}

There has been discussion about treating twenty-first century students as digital natives instead of digital immigrants. ${ }^{1}$ Collins ${ }^{2}$ indicated that the distribution of tech- nology adopters in Moore's Technology Adoption Cycle (innovators, early adopters, the early majority, the late majority, and laggards) follows a bell curve. Most people fall
Submission Date : 05-09-2014 Revision Date : :21-10-2014 Accepted Date : :23-12-2014

DOI:10.5530/jper.49.1.3 Correspondence Address Ching-Chiung Wang School of Pharmacy, College of Pharmacy, Taipei Medical University, No. 250 Wu-Xing Street, Taipei, Taiwan 11031. E Mail:crystalccwang@gmail. com

Shu-Chen Chien and ChingChiung Wang contributed equally to this work

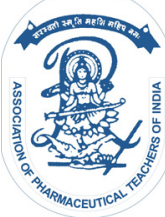

www.ijper.org 
into the categories of "early majority" and "late majority" (34\% and 34\%, respectively) and are open to new technologies. Therefore, scholars have indicated that the majority of learners today can learn effectively through digital learning.

The importance of complementary and alternative medicine is now widely recognized worldwide, even corpora such as the corpus of acupuncture on CQPWeb has been developed to provide standard translation of biomedical language. ${ }^{3}$ The World Health Organization (WHO) has published a formal translation of traditional medicine terminology in WHO International Standard Terminologies on Traditional Medicine in the Western Pacific Region. ${ }^{4}$ This further reveals the current significance of alternative medicine. ${ }^{5,6}$ Traditional Chinese Medicine (TCM) is one of the most commonly used alternative medicine and many researchers have been exploring its effective functions in regulating immune system activity, treating infectious diseases, and suppressing tumor growth..$^{7-9}$ Therefore, knowledge of TCM should be included in the education of medical school. For example, the University of Hong Kong is promoting integrative medicine by developing Chinese medicine programs that train students of both Western and Chinese medicine. ${ }^{10}$ In addition, educators have recognized that digitizing Chinese medicinal knowledge enables college students and the public to acquire effectively an awareness of the basic and clinical applications of Chinese medicine. ${ }^{11,12}$ These educators have expended effort into developing digital learning materials.

Scholars of educational technology, such as Richard E. Clark, ${ }^{13}$ have argued that comparing teaching methods that use different media is meaningless. However, TCMinstructors would benefit from determining whether digitized TCM instructional materials are as effective for students to learn the abstract concepts and terms of TCM as traditional classroom instruction. The concepts and terms used in TCM are mostly abstract, expressed in classical Chinese,and difficult for students and the public to acquire an awareness of in the present day.Furthermore, terms which appear in Western medicine often have different meanings in the TCM context, requiring teachers and students to carefully avoid misunderstandings.For instance, the meaning of the term "liver" ( "gan" in Mandarin Chinese) in Western medicine is different from its meaning in TCM. In Western medicine, the liver is an organ below the diaphragm necessary for digestion. However, "gan" in TCM does not solely refer to the same organ. Instead, it refers to a system, including the organ liver, blood stream, qi stream and much more. According to WHO, it "stores blood, facilitates the coursing of qi, and is closely related to the function of the sinews and eyes" (p. 22). Furthermore, it controls the functions of the autonomic nervous system. ${ }^{14}$ According to Edgar Dale's Cone of Experience ${ }^{15}$ (p. 143)verbal symbols (i.e., words) are the most abstract of all symbols on the concrete-abstract continuum. Learners can come to a more concrete understanding of verbal symbols through visual instructional activities, for example,activities using radios, still pictures, and movies. This is further supported by applying Paivio's dual-code theory, ${ }^{15,16}$ which contends that words (both abstract and concrete) visualized using pictures are more likely to be remembered by viewers because they are stored using both verbal and visual codes rather than just verbal codes. Our literature review found that various studies on digital learning instruction had been conducted in the area of conventional medical education. ${ }^{17-19}$ These studies have researched topics including active and reflective question usage in web-based instruction, ${ }^{17}$ video clip uses and collaborative learning tools in e-learning settings $;^{20}$ and the use of an interactive computer-based training program (ICBT) on dementia in different European countries. ${ }^{21}$ Cook et al. ${ }^{22}$ performeda meta-analysis on studies of simulation-based training for health professions education and identified effective instructional design features such as range of difficulty, repetitive practice, distributed practice, cognitive interactivity, multiple learning strategies, individualized learning, mastery learning, feedback, longer time for learning, and clinical variation. However, no studies have researched digital learning instruction on TCM. Consequently, this paper explains the development of TCM courseware and reports on the performance of students learning through traditional in-class lectures versus coursewareto provide insights into TCM education.

\section{Development of the Courseware}

In 2011, computer courseware designed to teach the fundamentals of Chinese medicine using two-dimensional animation was developed with the support of the Department of Chinese Medicine and Pharmacy, Ministry of Health and Welfare, Executive Yuan in Taiwan. Ten units on TCM were included: the origin and development of TCM; place of production and harvest of TCM; authentication of TCM; methods of processing and storage of TCM; characteristics of TCM; denomination and effects of TCM; application of TCM; safety medication of TCM; herb-flavored recipes; and the interactions of Western Medicine and TCM. Indigenous products and local herbal markets were also addressed in the unit materials (see Figure. 1). The 10 units were distributed to intended users for trial use. After receiving positive feedback from users, the Department of Chinese Medicine and Pharmacy placed the materials on a server accessible to the public. 


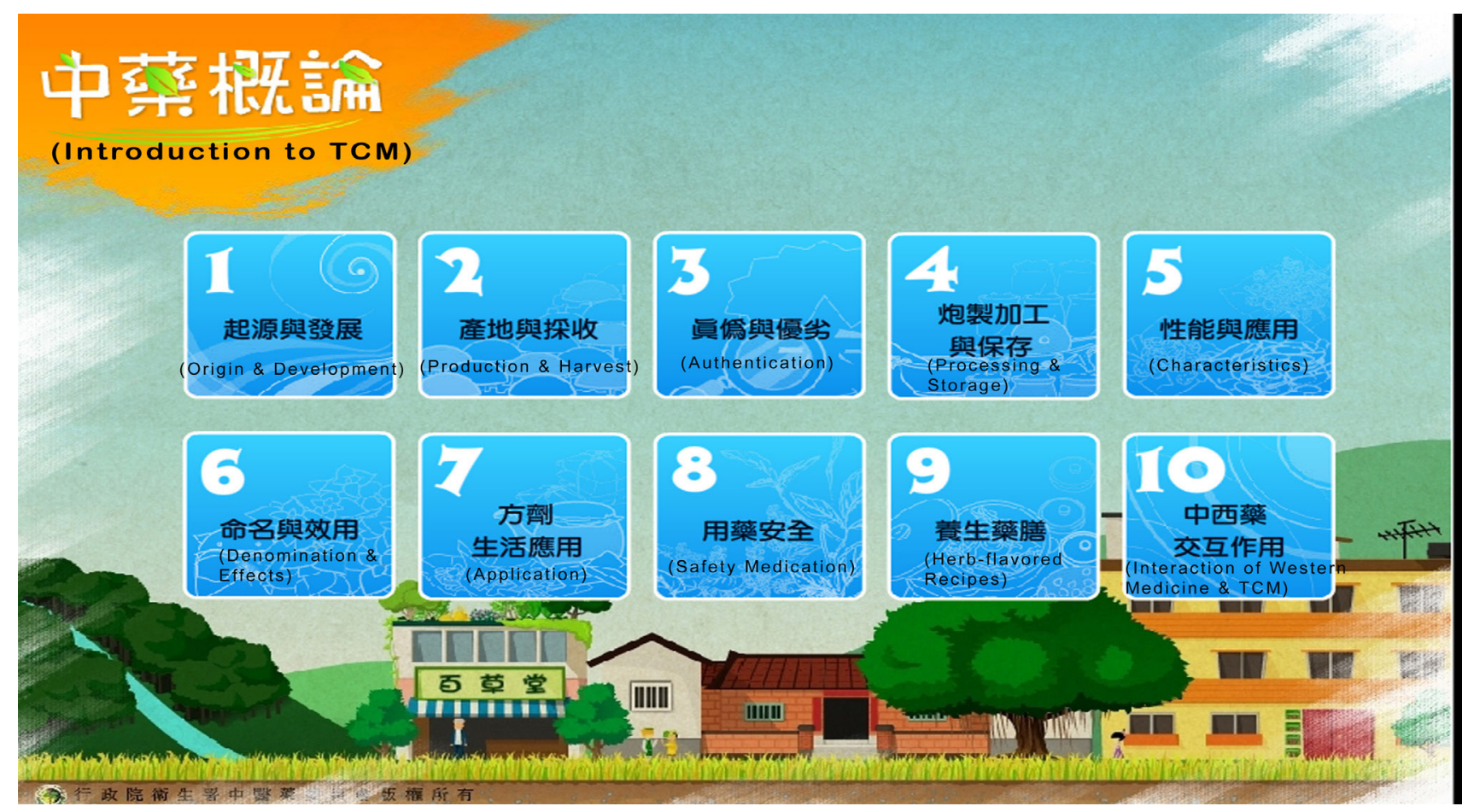

Figure 1: Ten courseware units

These are instructional computer programs with supporting materials. These materials can be produced on CD-ROM or DVD-ROMs which are portable for learners. Or they can be placed online on a server for users to access without the limit of time and space. :The contents in the courseware are all in Chinese originally. The English translations in brackets are added to the figures by the authors.
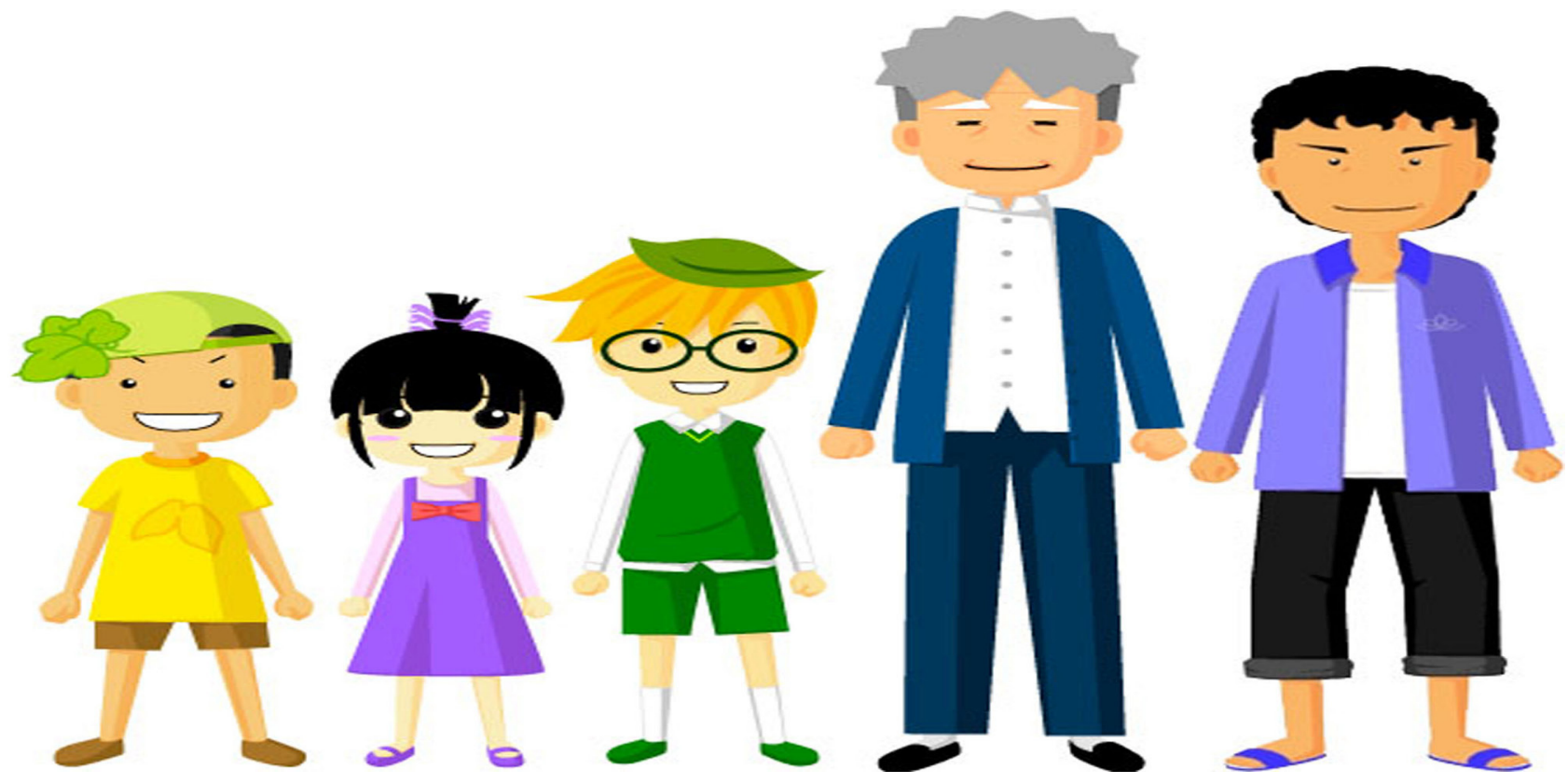

Figure 2: Characters in the digital learning units. 
To assure instructional quality, courseware was designed according to the nine events of instruction, which include gaining attention, presenting objectives, recalling prerequisite learning, presenting stimuli, providing guidance, eliciting performance, providing feedback, assessing performance, and enhancing retention and transfer. ${ }^{23}$ These events are embedded in the contents of the courseware.

The contents consist of instructional scenarios using text, audio and video, and two-dimensional animations. The details of the digital contents are as follows

\section{The characters and story}

There are five characters that live in Plum Village. One is a 60-year-old TCM physician, three are children in the sixth grade, and the last is a 50-year-old lotus farmer. These characters' names all refer to terms in Chinese medicine to raise the interest of users and allow them to relate to the subject of study. For examples, first, Ge Gen (Puerariae radix) is a medical herb in TCM treating common cold with headache and fever, ${ }^{24}$ and modern research has looked at its protections in human retinal pigment epithelial cells. ${ }^{25}$ Second, Huang Qin (Scutellaria baicalensis Georgi) helps to discard dampness and heat, ${ }^{24}$ and has anti-inflammatory ${ }^{26}$ and anti-bacterial effects. ${ }^{27}$ Third, Lei Wan (Laccocephalum mylittae) would kill parasites such as taeniasis, oxyuriasis, ancylostomiasis, and ascariasis. ${ }^{24,28}$ Fourth, Lei Gong Gen(Centella asiatica L.) would also help clear heat and harmful materials, ${ }^{29}$ and current research has indicated that it has anti-oxidative effect. ${ }^{30}$ Lastly, Chang Shan (Dichroa febrifuga) would fight against malaria, ${ }^{24}$ and has anti-inflammatory effect. ${ }^{31}$ As listed from left to right in Figure. 2, the characters corresponding to these Chinese herbs are: Ge Da Gen, who lives in Plum Village with his family including greatgrandparents; Huang Qin Mei, the prettiest girl in Plum Village; Lei Wan Wei, a child growing up in the city who has returned to visit his grandfather, Lei Gong Gen; Lei Gong Gen, a Chinese medical physician; and Ge Chang Shan, a farmer and father of Ge Da Gen.

The story is based on the children's daily activities in the 10 units, and as the children raise questions, they are answered by the TCM physician, Lei Gong Gen. The story begins when Lei Wan Wei, a child who lives in the city, returns to Plum Village to visit his grandfather, Lei Gong Gen, who is a TCM physician and owner of an herbal apothecary. Lei Wan Wei feels depressed because he is unfamiliar with the people and environs of the village. Lei Gong Gen decides to take Lei Wan Wei to Dihua Street to purchase Chinese herbs. On the way, they meet two other children in the village, Huang Qin Mei and Ge $\mathrm{Da}$ Gen, who join them on their trip. Along the way, Lei Gong Gen teaches the children about herbs. The other nine units are similar scenarios designed to contextualize the focus of the unit.

\section{Design features}

The digital learning units were designed using bright colors, which visually represent the non-mystical and scientific spirit of TCM to older and younger generations in the present day. The aim is for students and the public to accept and be willing to learn about Chinese medicine. Although the Chinese herbs taught in the courseware are mainly harvested and produced in different parts of China, to help students relate to the materials and to eliminate the sense of distance between them and their study subject, the story uses places and products in Taiwan. Herbs mentioned in the story include lian żi (lotus nuts) from Tainan, sān xing cōng (scallions) from Yilan, and dà zăo(jujubes) from Miaoli. The characters also visit Dihua Street in Taipei, famous for its Chinese medicine apothecaries.

\section{Contents of the units}

In each unit, there are (a) instructional goals and objectives, (b) interactive instructional contents, (c) a postunit summary, and (d) post-unit assessment items.

\section{Structure of the sections (approximately 50-60minutes per unit)}

The animated section in each unit includes each of the following items, not necessarily in the same order, and students are able to toggle back and forth between these items

- The opening: Introduction of the characters (3 minutes)

- Unit description by one of the children (3 minutes)

- Instructional content: Interactive instruction through two-dimensional animations of interaction between the children and the TCM physician (40-50 minutes)

- Main summary points by one of the children (3 minutes)

- Unit assessment: 10-30 multiple-choice questions (5 minutes)

- Closing: Introduction of the multimedia team (1 minute)

\section{Learning assessment}

At the end of each unit, the students were asked as many as 30 multiple-choice questions. At least 10 questions were intended for each of the three levels: populace (basic), apprentice (intermediate), and master (advanced). Questions were drawn randomly from a 


\section{等 级 表}

(Rating Scale)

\section{大師級 \\ (Master Level)}
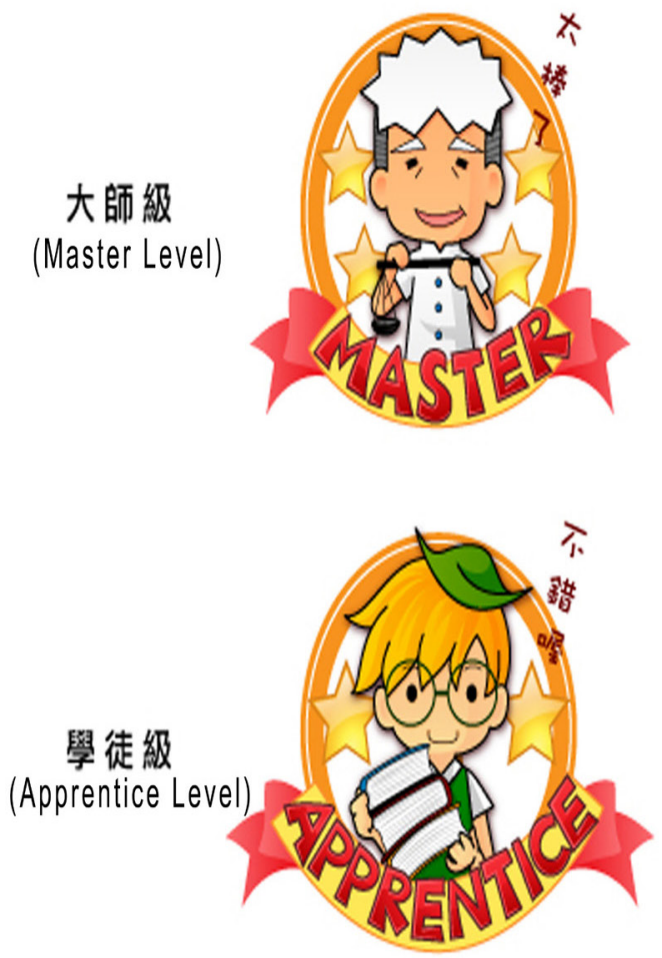

\section{普通級}

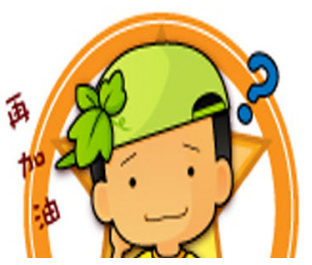

Figure 3: Three assessment levels

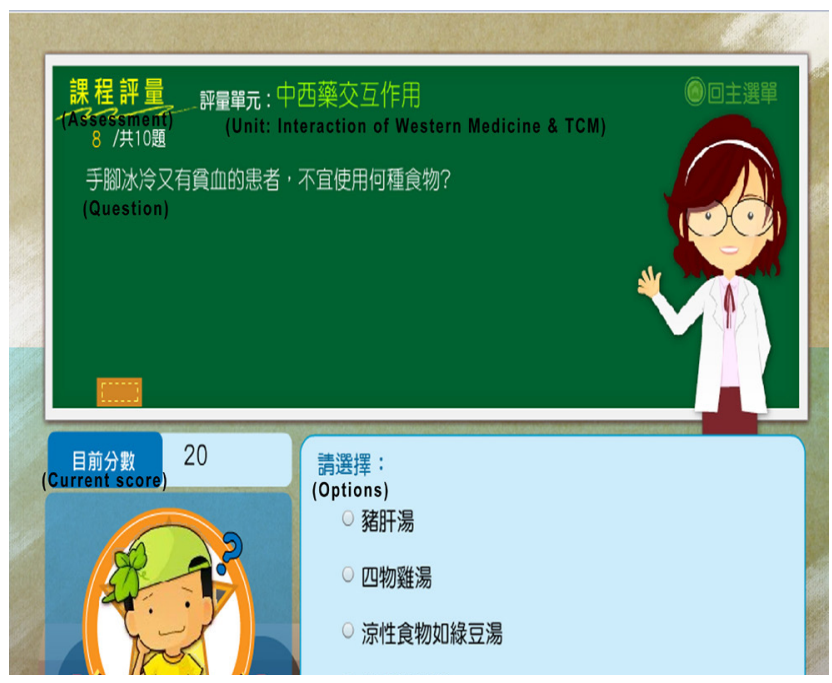

Figure 4: A sample of the assessment area (with the question)

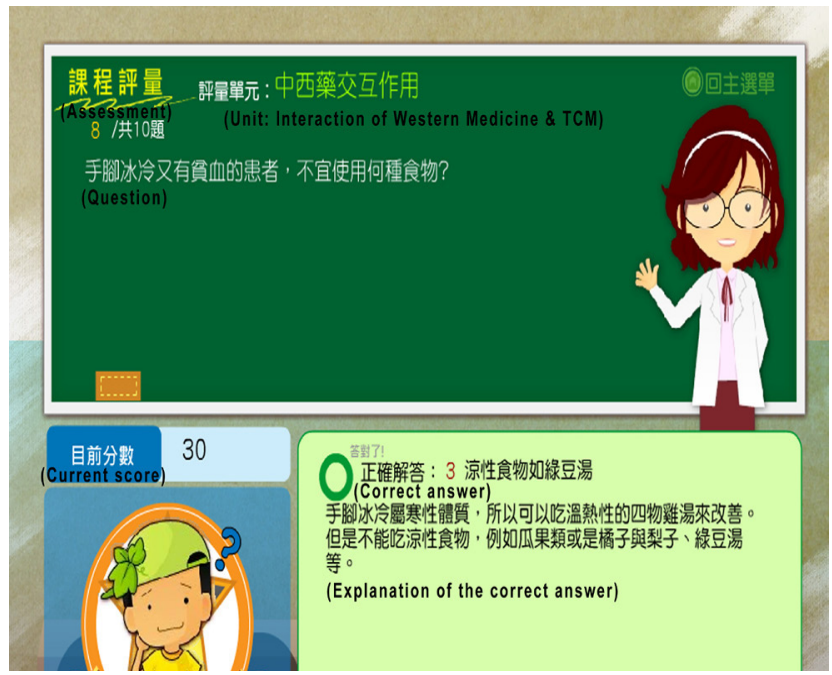

Figure 5: A sample of the assessment area (with the feedback)

bank of unit test questions. The students could proceed to the next level of assessment items only after passing the previous level (see Figure. 3 for the icons of the different levels, Figure. 4 for a sample assessment screen with a question, and Figure. 5 for a sample assessment screen with the feedback).

The editorial committee consisted of 11 experts, including Chinese medical practitioners and university professors in the areas of TCM and instructional design. The committee reviewed the scripts (characters and storyline), instructional contents, and assessment items of the different units. The committee also provided authorized pictures under copyright, photos, and relevant documents for the construction of the courseware. Following committee review, the digital production company storyboarded and produced the courseware. The editorial committee then trial-tested the courseware and provided feedback for revisions by the digital production company.

\section{METHODS}

This study adopted a mixed-method research design, including both quantitative and qualitative methods. The quantitative method enables the researchers to look at the learners' academic performances on the units learned while the qualitative feedback describes the experiences and suggestions of the participants.

\section{Pilot Study}

A pilot study was performed prior to data collection. Thirty-nine freshman-level college students in the medical university were invited to take part in this pilot study voluntarily. College students in all fields were recruited with the exception of pharmacy students (because students in the College of Pharmacy would be required to 
study TCM in their first year). Participants had no prior knowledge of TCM. Two units of reading materials were distributed to the reading group $(N=12)$ and computer courseware on DVD was distributed to the DVD learning group $(N=27)$. This activity was not conducted during the academic semester and reading materials were distributed to substitute for classroom lectures. The two units the participants studied were: Applications of TCM, and Interactions of Western Medicine and TCM. Students in both groups were tested before and after using the instructional materials. The tests consisted of multiple-choice questions designed by two editorial committee members who teach TCM at the university level. More than 200 questions were designed for expert review, and 90 questions were selected for the pre-test and post-test of this pilot study (45 questions with a total score of 45 in each test).

Because the sample sizes were small, we used non-parametric tests to compare pre-test and post-test scores. For the students in the reading group, the post-test results $(M d n=32.00)$ were significantly higher than the pre-test results $(M d n=26.00), \mathrm{Z}=-2.54, p=.011$. Likewise, for the DVD group, the post-test results ( $M d n=$ 32.00) were significantly higher than the pretest results $(M d n=22.00), \mathrm{Z}=-4.30, p=.000$, meaning that students in both groups improved between the two tests. However, the Mann-Whitney $U$ test showed that the differences between the post-test and the pre-test scores of the two groups (Reading: $M d n=8.00$; DVD: $M d n=$ 11.00) did not differ, $U=111.50, p=.123$. This outcome indicated that neither method was superior.

Qualitatively, the students who used the courseware expressed concerns that the speed of the narration and the audio dubbing were slow and monotonous, and suggested the addition of captions. The digital production company implemented these revisions after receiving this feedback.

\section{Participants and Instruments}

The participants in the actual study were volunteers recruited from freshmen enrolled in a compulsory undergraduate herbology course in the College of Pharmacy at a private medical university in Northern Taiwan. This course addressed the fundamentals of Chinese medicine. All students had to go through the units in this course, but they could choose whether or not to be part of this study. Of 200 students enrolled in the course, 198 students chose to take part in the study. Because they were in their first year of undergraduate study, they did not have any prior knowledge of the field. This means they were at the same starting point representing the general public who are without any background knowledge regarding TCM.
The study used the same instructional units used in the pilot study: Applications of the TCM, and Interactions of Western Medication and TCM. The 198 participating students were allowed to choose their mode of learning for these two units and became two groups, the lecture group ( $N=153)$ and the DVD group $(N=45)$. The lecture group was taught using the traditional lecture method in the regular class. By contrast, the DVD courseware group studied the two units on a DVDROM distributed to them individually in a computer lab during class time. Consistency in instruction was ensured because the instructor of the course was also the chief editor of the courseware editorial committee. As in the pilot study, both groups of students were pretested and post-tested. Each of these tests consisted of 45 questions selected from the test databank which undergone expert reviews for their appropriateness and validity. The instructor of the course did not handle the analyses of the test outcomes in order to avoid biases. The DVD group participants were also encouraged to give qualitative feedback regarding the courseware on a piece of paper upon the completion of the two units.

\section{Data Analysis}

Data analysis began with the test of normality to see if the post-pretest scores and their differences (the gain scores) were normally distributed. If they were normally distributed, then independent t-test and paired t-test would be conducted to see whether there were any differences in the improvement between the two groups and between their pre-test and post-test results. If the data were not normally distributed, then the nonparametric tests Mann-Whitney $U$ test and Wilcoxon Signed-rank test would be applied. These statistical analyses were performed using SPSS 20 (originally Statistical Package for the Social Sciences, now Statistical Product and Service Solutions).

\section{RESULTS}

The analyzed data provided results quantitatively and qualitatively. The quantitative data were analyzed using the Kolmogorov-Smirnov test (K-S test) to verify the normality of both the pre-tests and post-tests of the lecture group and the DVD group. We found that for the lecture group, neither pre-test scores $(D(121)=.177$, $p=.000)$ nor post-test scores $(D(121)=.189, p=.000)$ were normally distributed. The DVD group's pretest scores were normally distributed, $D(39)=.062, p=.20$, but post-test scores were not normally distributed, $D$ (39) $=.148, p=.032$. As a result, we used non-parametric tests to analyze the scores.

For the students in the lecture group, Wilcoxon Signedrank tests showed that there was a statistical significance 
and the post-test results $(M d n=34.00)$ were higher than the pre-test results $(M d n=25.00), Z=-7.14, p=.000$. Not surprisingly, for the DVD group, the post-test results $(M d n=33.00)$ were also significantly higher than the pre-test results $(M d n=23.00), Z=-5.17, p=.000$. However, the Mann-Whitney $U$ test showed that the score gains of the post-test and the pre-test scores of the two groups (Lecture: $M d n=9.00$; DVD: $M d n=10.00$ ) did not differ, $U=2124.00, p=.349$.

The students in the DVD group qualitatively shared their experiences of using courseware, and some indicated advantages. One student wrote, "The animation and pictures in the DVD courseware enhance my learning and memory of the Chinese herbs," and noted, "I can repeat and review the contents in the courseware as long as I want." Other students suggested including handouts to accompany the courseware, and increasing the number of types of herbs and the assessment items. Participants also noted that the courseware could promote knowledge of TCM and raise the public's interest if made accessible on the Internet, because of its lively designs and simplified explanations of the complicated subject matter. This positive feedback was implemented and the instructional contents are currently online and available to the public both on the websites of the Department of Chinese Medicine and Pharmacy, Ministry of Health and Welfare, Taiwan(see here for a unit: http://public.nacs.gov.tw/view/generalArea/lClass/ detail.do?id $=565775397749476 \&$ gaid $=10)$, as well as on the Open Courseware website of the university in Taipei where the study was conducted (for online and mobile learning, see here: http://ocw2.tmu.edu.tw/ podcasts $/ 8$ ?locale $=$ zh_tw).

\section{DISCUSSION AND CONCLUSION}

The study results showed that students taught using both traditional lecture methods and courseware demonstrated improved test scores after instruction. The difference between the post-and-pre-test scores (i.e., score gains) of the lecture group and the courseware group was statistically insignificant. As Gupta and Saks ${ }^{32}$ indicated, classroom lectures have multiple advantages and we do not seek to deny the effectiveness of live classroom teaching. Our result indicates that welldesigned courseware can be as effective as lectures to instruct students.

Designers of computer courseware should consider learning theories appropriate for student needs. The courseware used in this study presents instructional contents and interactive components according to wellknown instructional designer Gagné's nine events of instruction, ${ }^{23}$ starting with an interesting story to raise the student's attention, providing learning guidance, to the stage of enhancing information retention. Because the texts of TCM are mostly written in classical Chinese, the lively storyline and two-dimensional visualization help users understand the functions of various herbs. The participants of this study confirmed the effectiveness of the design, reporting that the animated instruction could reinforce their memorization of complicated herb names and functions. Because Asian people often take Chinese medicine and use Chinese herbs in daily cooking as a health strategy, ${ }^{33}$ such instruction is beneficial not only for pharmaceutical students but also for the public.

Simulated learning and learner control were also components which enabled students to retain knowledge successfully. The DVD courseware included scenarios simulating different situations, such as the use of TCM in the real-life situations, and correct and improper usages of TCM in conjunction with Western medicine. Liao and $\mathrm{Chen}^{34}$ performed a meta-analysis on studies of simulated computer instruction in Taiwan and found that simulated computer instruction has moderately positive effects on student academic achievement. Furthermore, the courseware allows learner control, which means the users themselves can choose and decide their paths and instruction speed. Computer courseware has at least three advantages for students: it meets student learning needs, it helps students develop a more robust understanding, and it reduces the amount of time necessary for accessing information. ${ }^{35}$ Student ability and learning speeds are heterogeneous. Learner control allows students to work at their own pace and repeat the program as many times as is necessary to gain sufficient understanding. For fast learners, the search and navigation functions save time, enabling them to move on to extended reading.

This study has illustrated the development of computer courseware designed to teach the abstract fundamentals of TCM according to educational learning theories. The courseware was created by TCM content experts, learning consultants, and a digital production team. The results reveal that students using courseware and students attending traditional classroom lectures both learned and improved in their test results. The visualization of abstract concepts, simulated scenarios, and the ability of learner control allowed students using courseware to learn as effectively as in the lecture setting. We do not advocate that computer courseware should replace traditional instruction or that it is acceptable for all students; however, because most students are digital natives of the twenty-first century and all learners have different learning preferences, computer and web-based courseware can be adopted either as supple- 
mental to the traditional classroom or for distance or blended teaching. Learners could also make good use of this type of materials for autonomous learning. Consequently, future studies could focus on students' learning style preferences and the effects of learning of TCM by using different instructional methods.

\section{ACKNOWLEDGEMENT}

Courseware design and development was supported by the grant from the Department of Chinese Medicine and Pharmacy, Ministry of Health and Welfare, Executive Yuan, Taiwan, R.O.C. (CCMP100-RD-032). The study was also partially supported by the Research and Development Grant of Fu-Jen Catholic University (No. A0102013). Comments from the anonymous reviewers of this manuscript and the editor of IJPER are also acknowledged.

\section{SOURCE(S) OF SUPPORT}

The development of the DVD courseware used in this study was funded by the Department of Chinese Medicine and Pharmacy, Ministry of Health and Welfare, Executive Yuan, Taiwan, R.O.C.

\section{CONFLICT OF INTEREST}

None

\section{REFERENCES}

1. Presky M. Digital natives, digital immigrants. On the Horizon [Internet]. 2001; 9(5): [cited 2013 July 15]. Available from: http://www.marcprensky.com/ writing/prensky\%20-\%20digital\%20natives, $\% 20$ digital\%20immigrants $\% 20$ -\%20part1.pdf.

2. Collins T. What's wrong right about ebooks for language learning? In: Leung $\mathrm{Y}$, Selected Papers from the Twenty-first International Symposium on English Teaching. Taipei,Taiwan: Crane; 2012. p. 34-9.

3. Budgell BS. The language of integrative medicine. J Integr Med. 2013; 11(3): 229-32.

4. World Health Organization (WHO). WHO International Standard Terminologies on Traditional Medicine in the Western Pacific Region [Internet]. 2007 [cited 2014 July 14]. Available from: http://www.wpro.who.int/ publications/docs/WHOIST 26JUNE FINAL.pdf.

5. Li ZG, Tan JM. Comparative study on WHO Western Pacific Region and World Federation of Chinese Medicine Societies international standard terminologies on traditional medicine: Diseases in External Medicine (Part 1). J Integr Med. 2013; 11: 67-71.

6. Li ZG. Comparative study on WHO Western Pacific Region and World Federation of Chinese Medicine Societies international standard terminologies on traditional medicine: Diseases of Gynecology and Obstetrics (Part 1). J Integr Med. 2014; 12: 127-30.

7. Ling CQ, Wang LN, Wang Y, Zhang YH, Yin ZF, Wang M, et al. The roles of traditional Chinese medicine in gene therapy. J Integr Med. 2014; 12(2): 67-75.

8. Ling $C Q$, Yue $X Q$, Ling $C$. Three advantages of using traditional Chinese medicine to prevent and treat tumor. J Integr Med. 2014; 12(4): 331-5.

9. Lee YW, Chen TL, Shih YR, Tsai CL, Chang CC, Liang HH, et al. Adjunctive traditional Chinese medicine therapy improves survival in patients with advanced breast cancer: a population-based study. Cancer. 2014; 120(9): 1338-44.

10. Chen HY, Feng Y, Lao L. Chinese integrative medicine: inclusion of a Chinese medicine programme in a conventional medical institute. $\mathrm{J}$ Integr Med. 2014; 12(3): 187-90.
11. Liang WL, Shih YD, Ling KS, Huang LH, Wang TM, Kang TH, et al. Evaluating the effectiveness of E-learning in fundamental of Chinese medicine education. Poster presented at the $16^{\text {th }}$ International Congress of Oriental Medicine; 2012 September 14-16; Seoul, Korea.

12. Shih BJ, Shih JL, Chen RL. Organizing learning materials through hierarchical topic maps: An illustration through Chinese herb medication. Journal of Computer Assisted Learning 2007; 23(6): 477-90.

13. Clark RE. Reconsidering research on learning from media. Review of Educational Research 1983; 53: 445-50.

14. Wu C. Basic theory of traditional Chinese medicine. Shanghai, China: Shanghai Pujiang Education Press; 2002.

15. Saettler P. The evolution of American educational technology. Englewood, CO: Libraries Unlimited, Inc; 1990.

16. Welcome SE, Paivio A, McRae K, Joanisse MF. An electrophysiological study of task demands on concreteness effects: Evidence for dual coding theory. Exp Brain Res. 2011; 212(3): 347-58.

17. Cook DA, Gelula MH, Dupras DM, Schwartz A. Instructional methods and cognitive and learning styles in web-based learning: Report of two randomized trials. Medical Education 2007; 41: 897-905.

18. Svirko E, Mellanby J. Attitudes to e-learning, learning style and achievement in learning neuroanatomy by medical students. Medical Teacher 2008; 30 : 219-27, doi: 10.1080/01421590802334275

19. Tan GJS, Hla YY, Surjadhana A, Kwan CY. E-mail group as a platform for communicating PBL pedagogy across national boundaries. Journal of Medical Education 2012; 16: 47-54.

20. Romanov K, Nevgi A. Do medical students watch video clips in eLearning and do these facilitate learning? Medical Teacher 2007; 29: 490-4.

21. Degryse J, De Lepeleire J, Southgate L, Vernooij-Dassen M, Gay B, Heyrman $J$. An evaluation of a computer based education program for the diagnosis and management of dementia in primary care. An international study of the trans cultural adaptations necessary for European dissemination. Medical Teacher 2009; 31: 397-402.

22. Cook DA, Hamstra SJ, Brydges R, Zendejas B, Szostek JH, Wang AT, et al. Comparative effectiveness of instructional design features in simulationbased education: Systematic review and meta-analysis. Medical Teacher 2013; 35: e867-98.

23. Gagné RM, Wager WW, GolasK, Keller JM. Principles of Instructional Design. 5th ed. Boston, MA: Wadsworth; 2004.

24. Ou M, editor. Regular Chinese medicine handbook. Taipei, Taiwan: Wang Wen Publishing; 1988.

25. Kim YS, Lee IS, Kim JS. Protective effects of Puerariae radix extract and its single compounds on methylglyoxal-induced apoptosis in human retinal pigment epithelial cells. Journal of Ethnopharmacology 2014; 152: 594-8.

26. Huang S, Huang Q, Huang B, Lu F. The effect of Scutellaria baicalensis Georgi on immune response in mouse model of experimental periodontitis. Journal of Dental Sciences 2013; 8: 405-11.

27. Duan $C$, Matsumura $S$, Kariya N, Nishimura M, Shimono T. In vitro antibacterial activities of Scutellaria baicalensis Georgi against cariogenic bacterial. Pediatric Dental Journal 2007; 17(1): 58-64.

28. Zhou L, Xu Q, Zhang Y, Zhou Z, Guan W, Li Y. Purification, characterization and in vitro anthelmintic activity of a Neutral Metalloprotease from Laccocephalum mylittae. Chinese Journal of Chemical Engineering 2010; 18(1): 122-8.

29. Huang TC, Chang YS, editors. The illustration of common medicinal plants in Taiwan Vol. II. Taipei, Taiwan: Committee on Chinese Medicine and Pharmacy, Department of Health, Executive Yuan, Taiwan; 2011.

30. Orhan IE, Atasu E, Senol FS, Ozturk N, Demirci B, Das K, Sekeroglu N. Comparative studies on Turkish and Indian Centella asiatica (L.) Urban (gotu kola) samples for their enzyme inhibitory and antioxidant effects and phytochemical characterization. Industrial Crops and Products 2013; 47: 316-22.

31. Park SY, Park GY, Ko WS, Kim YH. Dichroa febrifuga Lour. inhibits the production of IL-1 $\beta$ and IL-6 through blocking NF-KB, MAPK and Akt activation in macrophages. J Ethnopharmacol. 2009; 125(2): 246-51.

32. Gupta A, Saks NS. Exploring medical student decisions regarding attending live lectures and using recorded lectures. Medical Teacher; 2013. doi: 10.3109/0142159X.2013.801940

33. JiangS, Quave CL. A comparison of traditional food and health strategies among Taiwanese and Chinese immigrants in Atlanta, Georgia, USA. Journal of Ethnobiology and Ethnomedicine 2013; 9(1): 61. doi: 10.1186/1746-42699-61

34. Liao YK, Chen YW. The effect of computer simulation instruction on student learning: A meta-analysis of studies in Taiwan. Journal of Information Technology and Applications 2007; 2(2): 69-9.

35. Williams MD. Integrating technology into teaching and learning: Concepts and applications. Singapore: Prentice Hall; 2000. 